\title{
LÚPUS ERITEMATOSO CUTÂNEO: MANIFESTAÇÕES CLÍNICAS E ANÁLISE LABORATORIAL
}

\author{
Priscila Maria da Silva Gomes \\ Bióloga - Especialista em Análises Clínicas - Parasitologia - Faculdade Souza Marques (FSM) - RJ - Brasil \\ $\triangle$ biologia.psilva@gmail.com
}

\begin{abstract}
Resumo:
Lúpus eritematoso (LE) está incluído entre as chamadas doenças do tecido conjuntivo e é dividido em uma forma sistêmica o lúpus eritematoso sistêmico (LES) e uma forma cutânea lúpus eritematoso cutâneo (LEC). O LE é uma doença autoimune heterogênea e multissistêmica, caracterizada pela produção de anticorpos que combatem o seu próprio organismo em vez de combater a antígenos. O Lúpus é uma doença com maior frequência entre as idades de 20 a 50 anos, afetando mais as mulheres do que homens acometendo, em sua maioria, pacientes com uma história familiar de lúpus e outras doenças autoimunes.

Palavras-chave: Lúpus Eritematoso Cutâneo; Imunologia; Eritema; Fotossensibilidade.

\section{LUPUS ERYTHEMATOSUS CUTANEOUS: CLINICAL AND LABORATORY ANALYSIS}

\begin{abstract}
:
Lupus erythematosus (LE) is included among the so-called connective tissue diseases and is divided into a systemic form systemic lupus erythematosus (SLE) and a skin cutaneous lupus erythematosus form (LEC). The LE is a heterogeneous and multisystemic autoimmune disease characterized by the production of antibodies that fight your own body instead of fighting antigens. Lupus is a disease most frequently between the ages of 20 to 50 years, affecting more women than men involving, in most cases, patients with a family history of lupus and other autoimmune diseases.
\end{abstract}

Keywords: Cutaneous Lupus Erythematosus, Immunology, erythema, photosensitivity.

\section{LUPUS ERITEMATOSO CUTÁNEO: ANÁLISIS CLÍNICOS Y DE LABORATORIO}

\section{Resumen:}

El lupus eritematoso (LE) se incluye entre las llamadas enfermedades del tejido conectivo y se divide en una forma sistémica lupus eritematoso sistémico (LES) y una forma eritematoso piel lupus cutáneo (LEC). La LE es una enfermedad autoinmune heterogénea y multisistémica caracterizada por la producción de anticuerpos que combaten su propio cuerpo en lugar de antígenos que luchan. El lupus es una enfermedad con mayor frecuencia entre las edades de 20 a 50 años, que afecta a más mujeres que hombres que implican, en la mayoría de los casos, los pacientes con antecedentes familiares de lupus y otras enfermedades autoinmunes. Palabras clave: Lupus eritematoso cutáneo; Inmunología; Eritema; fotosensibilidad. 


\section{INTRODUÇÃO}

Lúpus é uma palavra derivada de lobo em latim e tem sido usado como nome de várias doenças de pele, pelo menos desde o Século X. O lúpus eritematoso (LE) está incluído entre as chamadas doenças do tecido conjuntivo e é dividido em uma forma sistêmica o lúpus eritematoso sistêmico (LES) e uma forma cutânea lúpus eritematoso cutâneo (LEC). Eles podem ocorrer tanto em conjunto e separadamente (GRÖNHAGEN e NYBERG, 2014).

O LE é uma doença autoimune heterogênea e multissistêmica, caracterizada pela produção de anticorpos que combatem o seu próprio organismo em vez de combater a antígenos. Segundo Sato et al. (2006), a etiologia ainda não é esclarecida e o desenvolvimento da doença está ligado à predisposição genética e a fatores ambientais, como luz ultravioleta e alguns medicamentos. A doença apresenta um amplo espectro de manifestações cutâneas e sistêmicas que tem sido objeto de investigação clínica e laboratorial no último século (KUHN, 2007).

O Lúpus Eritematoso Sistêmico (LES) é uma doença inflamatória crônica de etiologia multifatorial, caracterizada pelo envolvimento de diferentes órgãos e sistemas com desordens imunológicas com autoanticorpos. Ambos os sexos são afetados, com uma maior incidência em mulheres, principalmente em torno de 30 anos de idade. Sua etiologia não é bem definida, porem o favorecimento do LES associa-se com os fatores genéticos, fatores ambientais e emocionais ocasionando entre esses múltiplos fatores a desordem imunorreguladora (FILHO, 2014).

O entendimento da progressão e desenvolvimento de novas terapias para as doenças autoimunes, incluindo o Lúpus Eritematoso Cutâneo (LEC), é facilitado pelo desenvolvimento recente e os esforços para validar instrumentos resultado específicos ao LEC (ANYANWU, 2013). Durante as últimas três décadas, tem havido numerosas as tentativas de desenvolver instrumentos para medição de doença de pele. Os critérios usados pelo Dermatology Index of Disease Severity (DIDS) são muito gerais em suas avaliações das áreas de superfície corporal em relação ao lúpus, porém útil para doenças como acne ou LEC (ALBRECHT et al., 2005).

Doenças autoimunes estão associadas com severa redução da qualidade de vida de acordo com estudos de investigação da relação entre qualidade de vida e a gravidade do LEC. Embora muito progresso tenha sido feito na quantificação da severidade da doença na 
autoimunidade, ainda há dúvidas que não podem ser facilmente respondidas com resultados instrumentais (ANYANWU et al., 2013).

Segundo DAHL et al. (2012) o LEC é uma manifestação comum de lúpus eritematoso cutâneo crônico (LECC).

Contudo sua investigação epidemiológica do LEC tem sido prejudicada por uma escassez da apuração dos casos e muitos dos conhecimentos baseiam-se em pequenas e muitas vezes em estudos retrospectivos. Recentes estudos de base populacional têm mostrado que a incidência do LEC na Suécia e EUA são de 4/100.000 habitantes, em ambos os estudos, a maioria da população eram caucasianos (GRÖNHAGEN e NYBERG, 2014).

Com prevalência variando de 14 a 50/100.000 habitantes, em estudos norteamericanos. A doença pode ocorrer em todas as etnias e em todas as partes do mundo (SATO et al., 2006).

De acordo com Eastham e Vleugels (2014) o lúpus é uma doença com maior frequência entre as idades de 20 a 50 anos, afetando mais as mulheres do que homens acometendo, em sua maioria, pacientes com uma história familiar de lúpus e outras doenças autoimunes. Cerca de 1,9 a 6,8 mulheres para cada homem são acometidas pelo LECC.

\section{LUPUS ERITEMATOSO CUTÂNEO}

A forma cutânea do lúpus eritematoso apresentam três classificações, sendo elas: (1) lúpus cutâneo agudo; (2) lúpus cutâneo subagudo; e (3) lúpus cutâneo crônico ("lúpus discoide"). Os pacientes com lúpus cutâneo necessitam de uma atenção mais significativa nos pontos de articulações, rins, pulmões e outros órgãos. O lúpus cutâneo agudo (LCA) quase sempre envolve mais do que apenas a pele, ao contrário subagudo e lúpus discoide que muitas vezes ocorrem apenas na pele. Isto é importante porque, enquanto todos os pacientes com lúpus cutâneo precisam ser monitorados, muitos pacientes com lúpus subagudo ou discoide passar ao longo de sua vida sem danos significativos dentro de seus corpos (EASTHAM e VLEUGELS, 2014).

O LECC ou lúpus eritematoso discóide (LED) é uma dermatose crônica autoimune e variante clínica mais comum do LE. É desencadeado ou agravado pela exposição à radiação ultravioleta, frio, drogas e tem evolução vagarosa. As manifestações clínicas incomuns, como o lúpus comedônico, podem mimetizar outras doenças como acne vulgar, doença de Favre- 
Racouchot, milium, milia en plaque, siringoma, tricoepitelioma, poros dilatados agregados e nevo comedônico (FARIAS et al., 2011).

\section{LUPUS ERITEMATOSO CUTANEO AGUDO (LECA)}

Está quase sempre associado à forma sistêmica e o paciente mais típico são as mulheres de pele clara nos seus 30 anos. As lesões podem ser localizadas ou generalizadas (concentrada acima do pescoço). Eritema malar ou "eritema asa de borboleta" é a lesão localizada típica, um eritema (e/ou edema) sobre a eminência malar com tendência para poupar os sulcos nasolabiais; que muitas vezes vem após exposição ao sol com lesões que podem durar de horas a dias. A hiperpigmentação pós-inflamatória é comum, mas não ocorre cicatriz. O diagnóstico diferencial são erisipela, alergia de contato, dermatite seborreica, rosácea, fármaco indutor de reações fototóxicas e exantema viral.

A forma generalizada de LEC agudo embora menos frequente também está associada com uma exposição anterior ao sol com preferência localizado nas áreas expostas ao sol. O diagnóstico diferencial é dermatite tóxica, exantema viral e eritema multiforme (GRÖNHAGEN e NYBERG, 2014).

\section{LUPUS ERITEMATOSO CUTANEO SUBAGUDO (LECS)}

A maioria dos pacientes $(85 \%)$ é considerada fotossensível e as lesões estão localizadas principalmente em áreas expostas ao sol; pescoço, peito, costas, ombros, partes dorsais dos braços e mãos, mas surpreendentemente o rosto e couro cabeludo são raramente envolvidos. O LECS é mais comum entre os caucasianos com lesões em forma de placas eritematosas ou pápulas e, em seguida anulares. As lesões não são cicatrizes, mas muitas vezes curam com alterações pigmentares de longa duração fortemente associadas com o anticorpo Ro/anti-SSA, cerca de 70\% exibem o anticorpo, 60 - 80\% apresentam anticorpos antinuclear positiva (GRÖNHAGEN e NYBERG, 2014).

\section{LUPUS ERITEMATOSO CUTANEO CRÔNICO (LECC)}

As lesões começam como manchas eritematosas ou pápulas com uma superfície escamosa e depois crescer perifericamente em maior discoide placas que curam com cicatriz atrófica e alterações pigmentares. O envolvimento da mucosa é muito comum em pacientes LEC, pelo menos $25 \%$ dos pacientes LEC têm lesões nas mucosas, mas é provavelmente uma 
subestimação uma vez que muitos pacientes têm envolvimento assintomático, na maioria das vezes a mucosa bucal está envolvida. Os diagnósticos diferenciais são carcinoma basocelular, queratose actínica, líquen plano, superficial infecção fúngica, sífilis secundária, sarcoidose, cutânea tuberculose, hanseníase, cicatrizes (GRÖNHAGEN e NYBERG, 2014).

\section{SISTEMA IMUNOLÓGICO}

O nosso sistema imunológico tem a importante função no reconhecimento, ataque e eliminação das substâncias estranhas a sua composição, processo esse chamado de resposta imunológica que nos defende contra agentes infecciosos (ABBAS et al., 2013).

Segundo Martínez e Alvarez-Mon (1999), o sistema imunológico representa um sistema eficaz de defesa contra microrganismos que penetrem no organismo ou contra a transformação maligna de células, com a função de defesa essencialmente contra o desenvolvimento de infecções e tumores. Esta capacidade de defesa do sistema imunológico se fundamenta na ativação das células efetoras, que incluem os linfócitos e as células apresentadoras de antígenos ou acessórias.

O sistema imunológico compreende as vias principais através das quais o ser humano responde se adaptando aos desafios exógenos e endógenos. Está formado por uma série de células e moléculas, distribuídas pelo organismo, imprescindíveis para a sua defesa frente a infecções e/ou situações que comprometam a sua integridade. As proteínas do sistema imunológico representam 20 a 25\% da concentração de total de proteínas plasmáticas e o seu componente celular representa aproximadamente $15 \%$ das células corporais (MARTÍNEZ e ALVAREZ-MON, 1999).

Nos linfócitos, as principais ações da vitamina D são: alteração na secreção de citocinas pró-inflamatórias, como a diminuição de Interferon- $\gamma$ e a Interleucina-2 (IL-2), bloqueando, assim, o principal sinal de retroalimentação das células dendríticas, gerando uma diminuição da capacidade de apresentação de antígenos aos linfócitos e diminuição da ativação e expansão clonal dos linfócitos. Ao mesmo tempo, ela aumenta a produção de IL-4, IL-5 e IL-10, e gera uma mudança de fenótipo T helper I para T helper II o que leva a uma maior tolerância imunológica, contudo a ação da vitamina D sobre o sistema imune também afeta a subpopulação de linfócitos Th17. Esses linfócitos T helper se caracterizam por secretar IL-17 e com isso participam na fisiopatogenia das doenças autoimunes. Outras citocinas também sofrem diminuição na sua produção na presença de vitamina D, como IL-6, IL-12 e IL-23 (TEIXEIRA e COSTA, 2012). 
Embora sua distribuição seja universal, essa enfermidade é três vezes mais frequente em afro-americanos do que em brancos e dez vezes mais em mulheres. Vários autores têm demonstrado maior prevalência da deficiência de vitamina D em pacientes com LES em comparação a indivíduos saudáveis ou com outras doenças reumatológicas. Pesquisas sugerem uma relação entre a deficiência da vitamina $\mathrm{D}$ e o desenvolvimento da enfermidade. Ensaios in vitro mostraram que a suplementação de vitamina D diminui as anomalias características do LES. Sugere-se que as alterações imunológicas causadas pelo déficit de vitamina D possam levar a uma diminuição da tolerância imunológica, permitindo o desenvolvimento de doença autoimune em indivíduos geneticamente predispostos (TEIXEIRA e COSTA, 2012).

\section{DOENÇAS AUTOIMUNES}

As respostas inadequadas do sistema imunológico geram o que conhecemos como doenças, fazendo com que o sistema imune se volte contra o seu organismo reagindo contra órgãos, tecidos ou células próprias, podendo assim destruir a sua função original. Contudo a tolerância imunológica aos antígenos próprios ocorre principalmente no timo por mecanismos que eliminam ou inativam linfócitos $\mathrm{T}$ autoreativos através de deleção clonal, anergia clonal ou supressão. Em sua totalidade de linfócitos $\mathrm{T}$ imaturos provenientes da medula óssea que chegam ao timo, apenas $5 \%$ atingem a circulação periférica, sendo intensa a taxa de apoptose. As células que chegam à periferia são imunocompetentes contra antígenos estranhos, porém incapazes de desenvolver resposta imune contra seus próprios antígenos (BUENO e PACHECO-SILVA, 1999).

\section{EPIDEMIOLOGIA}

O estudo epidemiológico tem sido dificultado pela falta de apuração dos casos que na maior parte do conhecimento é baseado nos poucos estudos retrospectivos. Estudos de base populacional têm mostrado que a incidência de LEC na Suécia e EUA é de 4/100.000 habitantes (GRÖNHAGEN e NYBERG, 2014). No Brasil, a prevalência da doença varia de 14,6 a 122 casos por 100 mil habitantes, contudo a cidade de Natal-RN parece ter a maior incidência de habitantes/ano, em estudo realizado no ano 2000 (BEZERRA et al., 2005).

É descrito na literatura uma maior incidência de LES em mulheres. Estudos recentes nas cidades de Cascavel (Paraná) e Natal (Rio Grande do Norte) apontaram uma incidência de 
9,3 e 14,1 casos por 100.000 habitantes, com prevalência e mulheres (NAKASHIMA et al., 2011).

Portanto, as incidências em alguns estados do Brasil são altas e outras baixas para o desenvolvimento do LE, pois é intimamente influenciado pelas diferentes condições climáticas, o que pode influenciar no aparecimento da doença e de suas complicações, como a do LEC com grande sensibilidade aos raios ultravioleta (KLEIN et al., 2011).

\section{DIAGNÓSTICO}

O Cutaneous Lupus Erythematosus Disease Area and Severity Index (CLASI) é uma ferramenta clínica que quantifica a atividade e o dano causado pelo LEC (ALBRECHT et al., 2005). É utilizado para padronizar a forma como a atividade da doença é descrita e fornece diretrizes para a identificação de alterações clínicas quantificando a atividade e os danos da doença. O índice de atividade é baseado no grau de eritema, lesões das mucosas e alopecia. Ao contrário de outras medidas, a pontuação CLASI não é baseada unicamente na área da pele envolvida, mas sim, partes do corpo que são mais visíveis, mais ponderadas do que aquelas que estão geralmente cobertas (UVA et al., 2012).

De acordo com o American College of Rheumatology o diagnóstico de LES é baseado na avaliação de anticorpos antinucleares: título anormal de anticorpo antinuclear por imunofluorescência indireta ou método equivalente, em qualquer época e na ausência de drogas conhecidas por estarem associadas à síndrome do lúpus induzido por fármacos (BORBA et al., 2008).

\section{CRITÉRIOS LABORATORIAIS}

O diagnóstico das manifestações cutâneas de LE baseia-se nas análises clínicas, histopatologia e imunohistologia das lesões cutâneas. Além disso, os autoanticorpos no soro são considerados marcadores imunológicos para tipos distintos de clínicas da doença.

Nos ensaios imunológicos, são avaliados a presença de anticorpo anti-DNA nativo ou anti-Sm, ou presença de anticorpo antifosfolípide baseado em níveis anormais de $\operatorname{IgG}$ ou $\operatorname{IgM}$ anticardiolipina, ou em teste positivo para anticoagulante lúpico ou teste falso positivo para sífilis, por no mínimo seis meses (BRAGA et al., 2003). 
Exemplificam os dados laboratoriais de rotina diante dos problemas de um paciente caucasoide do sexo feminino, iniciando manifestações de púrpura trombocitopênica imunológica (PTI) aos 7 anos, tratada com pulsoterapia de metilprednisolona (30 mg/kg/dose) e corticoide oral $(1 \mathrm{mg} / \mathrm{kg} / \mathrm{dia})$.

Diante dos problemas a criança, com 8 anos e 8 meses, manifestou pericardite, erupções faciais, fotossensibilidade e anemia hemolítica autoimune (AHAI) com testes de Coombs direto (TCD) e testes de Coombs indireto (TCI) positivos. Portando para o diagnóstico do lúpus eritematoso sistêmico juvenil (LESJ) nesta criança foi possível pelo exame laboratorial que apresentava $\mathrm{Hb} 5,6 \mathrm{~g} / \mathrm{dL}$; hematócrito (Htc) 19\%; leucócitos $2.900 / \mathrm{mm}^{3}$; plaquetas $20.000 / \mathrm{mm}^{3}$; FAN (padrão homogêneo periférico) e anti DNA positivos, CH50 diminuído (34\%) e ACL negativo.

O fator antinuclear (FAN) na figura 1, usa como substrato células HEp-2 é a metodologia de escolha para rastreamento e identificação dos padrões de imunofluorescência à qual os diversos autoanticorpos se associam (LORA et al., 2007).

Figura 1 - Teste de fator antinuclear (FAN) positivo.

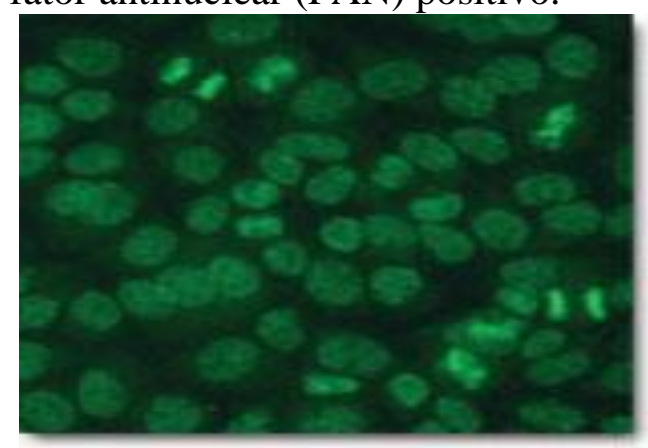

Fonte: PODCASTING BRASIL, 2011.

A correlação da resposta clínica com biomarcadores vem se consolidando e se tornando um meio importante para esclarecer as vias moleculares na base da patogênese da doença autoimune cutânea e fornecer uma avaliação independente no início da eficácia da terapia (ANYANWU et al., 2013).

\section{Análises Clínicas}

Os exames como hemograma com contagem de plaquetas, glicemia de jejum, provas de função renal e hepática, proteínas totais e fração, proteína $\mathrm{C}$ reativa, mucoproteína, fator reumático, VDRL, anti-SM, complemento total e frações, urina I e protoparasitológico de 
fezes, contudo é importante salientar que os anticorpos antinucleares (FAN) são positivos em 70 a 90\% dos casos de LEC (ROMITI et al., 2004).

\section{Histopatologia}

Notório que em pacientes com lúpus eritematoso cutâneo discoide (LECD) têm idade e duração da doença significantemente mais longa do que os pacientes com LES ( $p<0,04)$, sendo de extrema importância à realização da biópsia da pele nos pacientes com LECD para o diagnóstico de e confirmação do LECD em 62,5\% dos pacientes. Nos demais pacientes o diagnóstico de LECD foi clínico e foram descartadas outras doenças no estudo histopatológico da pele (MARÇON et al., 2004).

\section{Lesões Cutâneas}

O lúpus eritematoso cutâneo denomina-se lúpus eritematoso verrugoso ou hipertrófico, pois tem a presença de lesões discoides preexistentes em áreas expostas ao sol com o surgimento de lesões papulonodulares verrucosas, podendo surgir em placas, algumas vezes com tampão central, dando a lesão à aparência de queratoacantoma (BERBERT e MANTESE, 2005).

A forma de LECC mais comum é o lúpus eritematoso discoide localizado (LEDL), caracterizado por lesões maculosas ou populosas, eritematosas, bem definidas, com escamas firmes e aderentes a superfície das lesões. Essas lesões tornam-se mais infiltradas e confluentes, formando placas recobertas por escamas espessas e queratose que se estende para o interior do folículo piloso dilatado (BERBERT e MANTESE, 2005) como pode ser visto na figura 2. Essas lesões evoluem centrifugamente, assumindo forma de disco, muitas vezes com alterações discrômicas, presença de telangiectasias e deixando cicatriz atrófica central e, no couro cabeludo, alopecia e cicatricial (FREITAS et al., 2003).

O lúpus túmido é um subtipo raro do LECC, apresentando clinicamente eritema, lesões urticariformes ou placas lisas, eritematosa violácea, brilhante, localizada na cabeça e no pescoço, muitas vezes com descamação fina discreta. As lesões podem apresentar prurido, contudo ao evoluírem não deixam cicatrizes e, quando recorrem, o fazem nos locais originalmente afetados (BERBERT e MANTESE, 2005).

O envolvimento da pele de LEC em fase aguda, conhecido como LECA, compreende o eritema e edema malar, que frequentemente se estende para trás da ponte nasal e constitui a chamada "eritema em asas de borboleta" destacada na figura 4 e exantema morbiliforme 
indistinguível de infecções virais ou toxico dérmica. Cerca de $25 \%$ dos pacientes apresentam ao longo da sua placas discoides (BERBERT e MANTESE, 2005).

Clinicamente, no LEC subagudo, as lesões são apresentadas pela descamação, sendo elas, lesões de placas eritematosas e descamativa ou anulares, sendo estes visualizados na figura 5 e 6 . Os tratamentos convencionais incluem o uso de filtros solares, os corticosteróides tópicos e orais, sulfona, antimaláricos e agentes imunossupressores, tais como ciclosporina, azatioprina ou metotrexato (GUILLERMO et al., 2009).

Figura 2 - Lúpus cutâneo crônico localizado

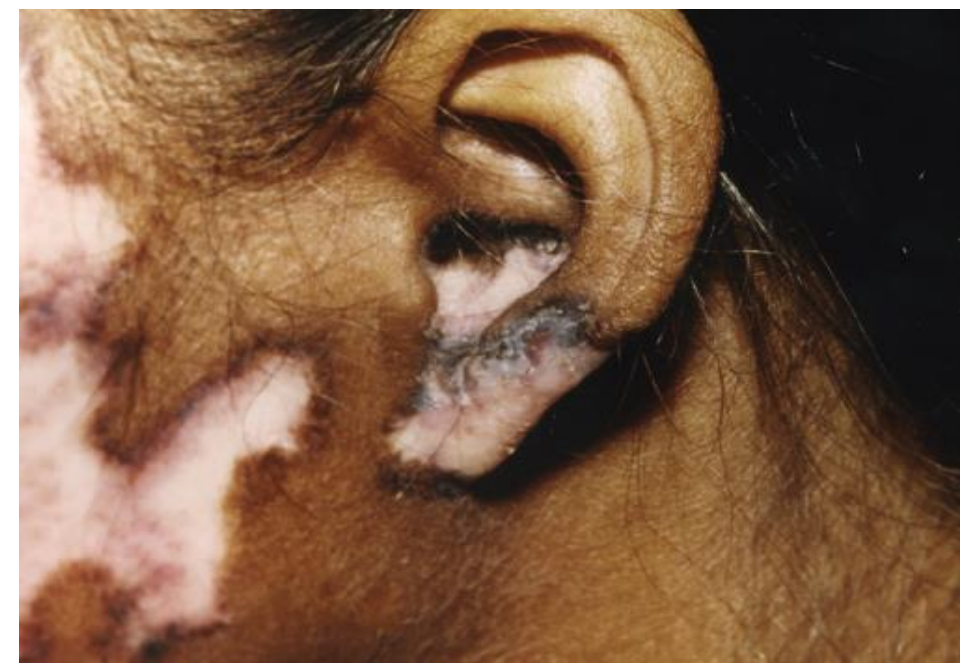

Legenda: Lesão lúpica apresentando placa eritematosa, levemente descamativa, atróficocicatricial, discrômicas, com bordas hipercrômicas e queratósicas, localizadas na hemiface esquerda.

Fonte: BERBERT e MANTESE, 2005

Figura 3 - Lúpus eritematoso cutâneo crônico hipertrófico

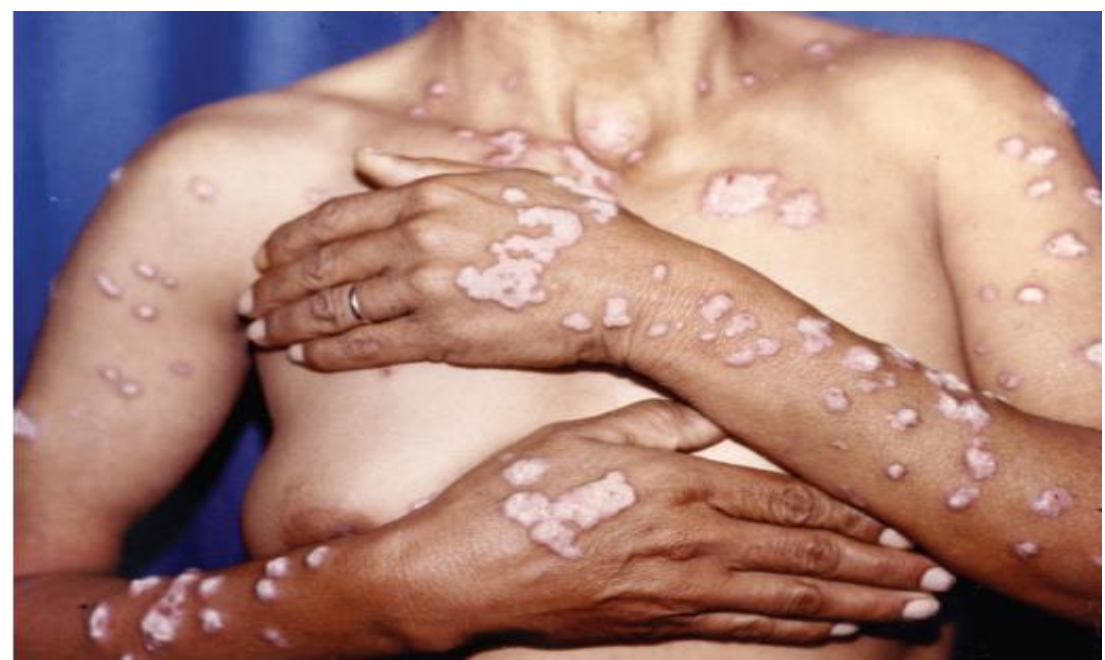

Legenda: Nódulos e placas eritematosas descamativas e hiperqueratosicas disseminadas.

Fonte: BERBERT e MANTESE, 2005 
Figura 4: Lúpus cutâneo crônico túmido

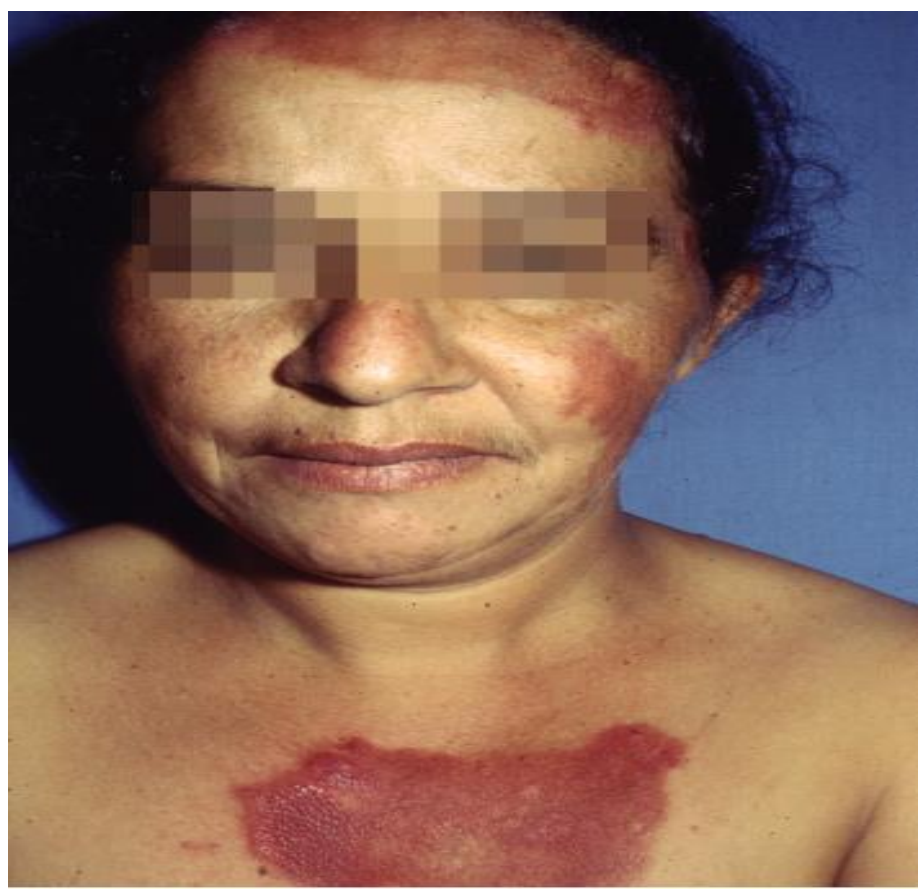

Legenda: Placas eritematosas edematosas na face e tórax. (Servico de Dermatologia da UFMG).

Fonte: BERBERT e MANTESE, 2005

Figura 5: Lúpus subagudo anular

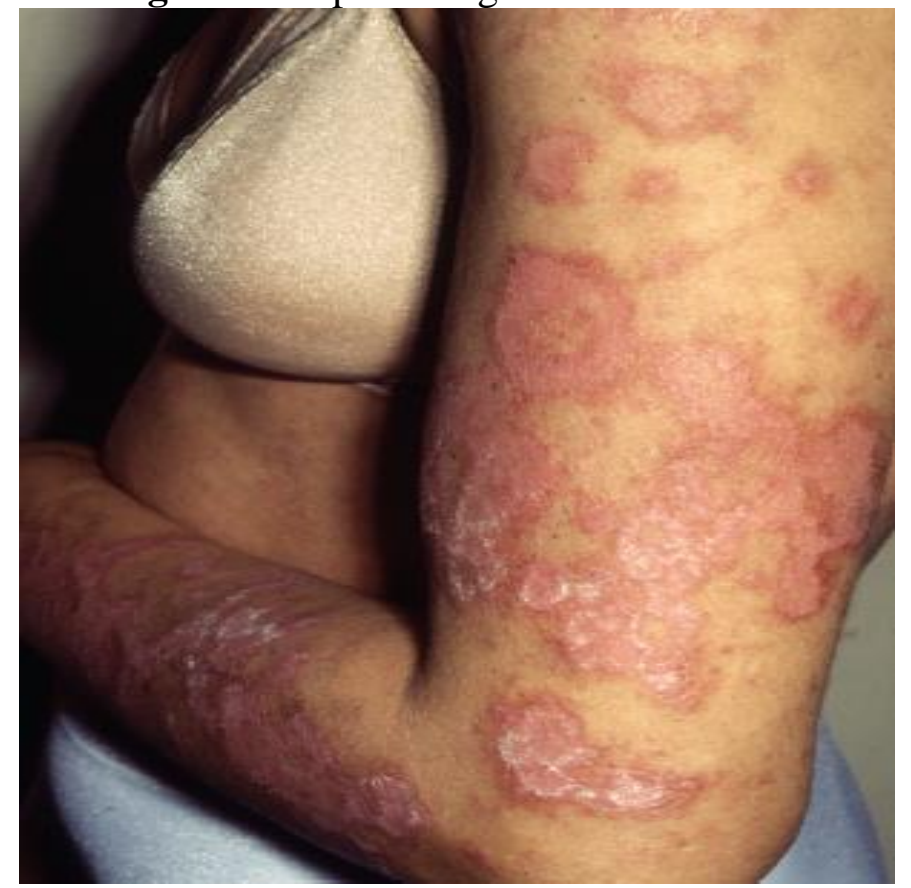

Legenda: lesões eritematodescamativas, anulares, em arranjo policíclico, localizadas no membro superior. Serviço de Dermatologia da UFMG.

Fonte: BERBERT e MANTESE, 2005 
Figura 6: Lúpus cutâneo agudo

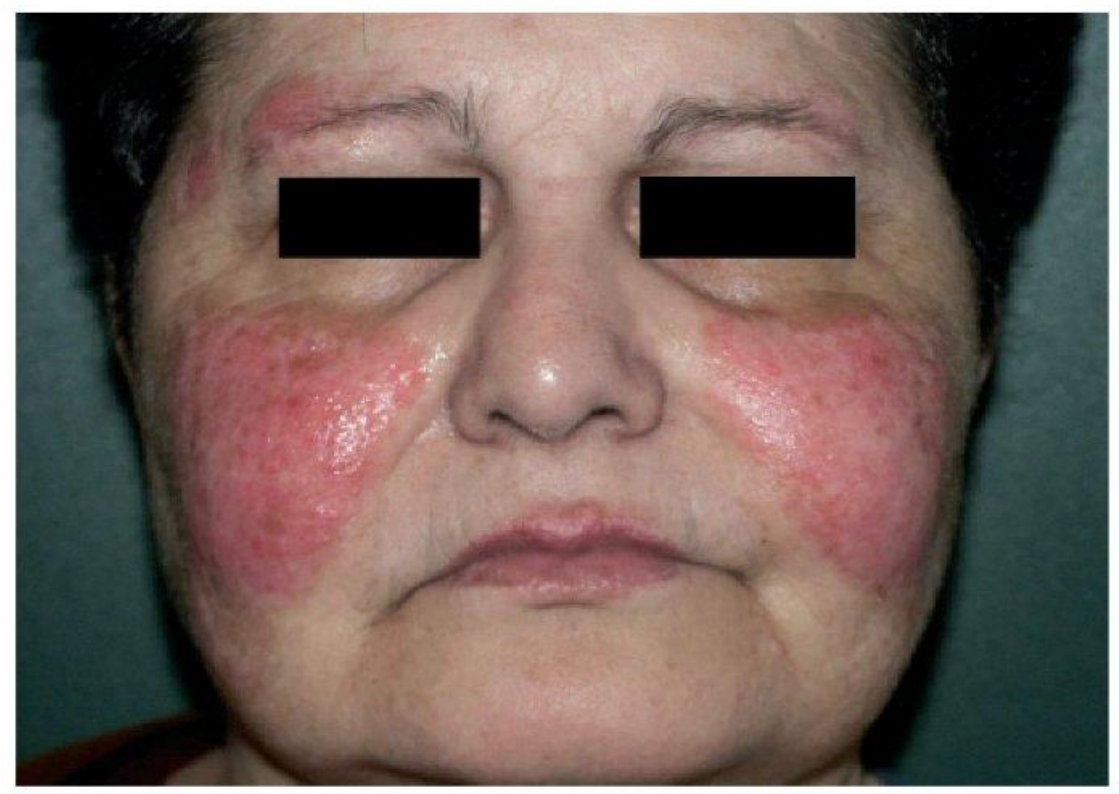

Legenda: Placas eritematosas infiltradas nas sobrancelhas, bochechas e pele do lábio superior. Fonte: GUILLERMO et al., 2009.

\section{TRATAMENTO}

Atualmente o tratamento do LEC consiste na utilização de corticóides tópicos, antimaláricos e imunossupressores, contudo alternativas recentes começam a ser introduzidas para o tratamento.

\section{Corticoides tópicos (CS)}

Em lesões isoladas ou refratárias o tratamento local é mais indicado e atualmente existem diversas preparações disponíveis. Os corticosteroides podem ser divididos em fluorados e não fluorados e podem ser de baixa, média e altas potências. Dentre os corticosteroides não fluorados está a hidrocortisona. Apesar de serem mais baratos, são menos potentes do que os fluorados. Entretanto, os corticosteroides fluorados produzem mais efeitos adversos, como atrofias, despigmentações, estrias, acne, foliculites e superinfecção por Candida sp, portanto, não devem ser usados por mais de duas semanas (RIBEIRO et al., 2008).

Reduzem efetivamente os sintomas inflamatórios em todos os tipos de CLE. Apesar de anos de uso clínico, existe apenas um estudo controlado randomizado, em que alta potência de $0,05 \%$ creme fluocinonide foi mais eficaz do que baixa potência $1,0 \%$ creme de 
hidrocortisona em 78 pacientes com a terapia tópica. CS é conhecido por causar atrofia telangiectasias e rosácea dermatite induzida por esteróides. O CS deve ser prescrito com a menor potência necessária para alcançar resolução para o curto espaço de tempo. Em geral, CS de baixa ou média potência (por exemplo, metilprednisolona) deve ser usado no rosto; os de média potência (por exemplo, triancinolona, valerato de betametasona) no tronco e extremidades, e os de alta potência (por exemplo, clobetasol) nas palmas das mãos e plantas dos pés, onde a pele é mais grossa. Terapia intralesional com 2,5 a solução triancinolona $10 \mathrm{mg} / \mathrm{mL}$ pode ser útil (WINKELMANN et al,. 2013).

\section{Antimaláricos}

O uso de quinina e a quinacrina apresenta eficácia no tratamento do LEC sendo utilizada para o tratamento de outras manifestações clínicas do LES, melhor resposta terapêutica das manifestações cutâneas.

Os antimaláricos mais estudados e utilizados são a hidroxicloroquina, a quinacrina e o difosfato de cloroquina. A dose recomendada da hidroxicloroquina é de $6,5 \mathrm{~m} / \mathrm{kg} / \mathrm{dia}$, com maior precaução quanto a sua toxidade retiniana (RIBEIRO et al., 2008). Contraindicações para a terapia incluem pacientes com hipersensibilidade a 4-amino-quinolonas, retinopatia, doenças hematopoiéticas, deficiência de glicose-6-fosfato e miastenia gravis (WINKELMANN et al., 2013).

\section{Imunossupressores}

Não há evidência suficiente na literatura sobre o emprego de imunossupressores no tratamento do LEC. Todavia, lesões graves que parecem ser irreversíveis podem, de fato, apresentar melhora com o tratamento imunossupressor mais agressivo, que muitas vezes é iniciado para manifestações mais graves do lúpus, como nefrite ou cerebrite. Sendo assim, esses fármacos constituem terapia de terceira linha no tratamento do LEC (RIBEIRO et al., 2008).

\section{Rituximab}

É um anticorpo monoclonal quimérico anti-CD20 em células B, sendo aprovada para o tratamento de linfoma não-Hodgkin moderado a grave da artrite reumatoide (RA). Contudo, uma série de casos precoces sugeriu a possibilidade do uso da rituximab atuando na atividade grave em LES, que forneceu a justificativa de um estudo mais aprofundado para o tratamento em pacientes com LES fornecendo a justificativa para mais estudo desse tratamento em pacientes com LES (MERRILL et al., 2011). 
A terapia combinada com rituximab e ciclofosfamida resultaram em redução significativa na média de prednisona dosagem, a taxa de sedimentação de eritrócitos (LEHMAN et al., 2014). Em 2000, a literatura inclui inúmeras séries e meta-análise de apoio à célula $\mathrm{B}$ terapia de esgotamento, incluindo uma revisão sistemática de 188 portadores de doença grave, refratária mostrando 91\% tinha melhoria significativa em pelo menos uma manifestação lúpus (BELMONT, 2013).

\section{Ciclofosfamida}

É um fármaco antitumoral usado para tratar vários tipos de câncer e algumas desordens autoimunes. Estudos recentes demonstraram que a terapia combinada de rituximab com ciclofosfamida resultou em redução significativa na dosagem de prednisona, taxa de sedimentação de eritrócitos e LES (LEHMAN et al., 2014).

\section{Uso de filtro solar}

As irradiações ultravioletas A (UVA) e B (UVB) caracterizam lesões significativas em pacientes com LEC, sendo fundamental uma introdução educacional sobre a diminuição da exposição ao sol e raios UV em pacientes com LEC.

A utilização do protetor solar com FPS 50 ou maior em quantidades adequadas deve ser aplicada em pacientes com LEC. Além disso, suplementação de vitamina D (400 UI/dia) deve ser sempre considerada nesses pacientes, aconselhando evitar o sol (WINKELMANN et al., 2013).

\section{Inibidores da calcineurina}

Devido aos efeitos adversos dos CS, inibidores da calcineurina, tacrolimus e pimecrolimus, têm sido estudados por seu potencial terapêutico de longo prazo no CLE. Desde os primeiros relatos de sucesso com inibidores da calcineurina no tratamento de lesões cutâneas do lúpus, em 2002, vários estudos têm demonstrado a sua eficácia em efeitos adversos no CLE. Está limitada a queima transitória, eritema e irritação sem o risco de atrofia da pele. Os inibidores de calcineurina são particularmente eficazes em áreas sensíveis da pele, incluindo o rosto, pescoço e áreas intertriginosas (WINKELMANN et al., 2013).

\section{Clofazimina}

É um antibiótico com atividade imunossupressora e anti-inflamatória, tradicionalmente utilizada no tratamento da hanseníase. Este tratamento pode gerar algumas alterações na pele como a descoloração marrom avermelhada, pele seca, náuseas e diarréia. 
Devido à incapacidade de se determinar se existe um risco de induzir lesões CLE com clofazimina, só é indicado em pacientes com manifestações cutâneas de doença exclusiva (WINKELMANN et al., 2013).

\section{CONSIDERAÇÕES FINAIS}

A necessidade de maiores informações sobre a etiologia, os sintomas, diagnósticos e tratamentos do LEC possibilitou a realização da revisão bibliográfica junto aos livros e artigos científicos, porque em sua maioria os dados transmitidos são quadros clínicos do LEC, doença capaz de levar o paciente ao sofrimento, ao choro, frustações e a perdas advindas da patologia ainda que sua etiologia não seja desconhecida.

Desta forma se podermos transferir o máximo de informações sobre os seus sintomas principalmente, evitando assim um diagnóstico tardio com a possibilidade de um tratamento rápido e eficaz, devido à abordagem interdisciplinar entre as dimensões biológica, psicológica e social. Há muitos problemas com a convivência com a doença, contudo estudando melhor suas complicações entenderemos que a doença não impede a criação de expectativas quanto ao futuro dos jovens na construção familiar ou na carreira profissional, muito menos aos adultos que já passaram por essa fase da vida e esperam agora poder manter o controle do doença e criar saudavelmente seus filhos e netos. 


\section{REFERÊNCIAS BIBLIOGRÁFICAS}

ABBAS, A. K.; LICHTMAN, ANDREW, H.. Imunologia Básica. Rio de Janeiro: Elsevier, 2013.

ALBRECHT, J.; TAYLOR, L.; BERLIN, J. A.; DULAY, S.; ANG, G.; FAKHARZADEH, S.; KANTOR, J.; KIM, E.; MILITELLO, G.; MCGINNIS, K.; RICHARDSON, S.; TREAT, J.; VITTORIO, C.; VOORHEES, A. V.; WERTH, V. P.. The CLASI (Cutaneous Lupus Erythematosus Disease Area and Severity Index): An Outcome Instrument for Cutaneous Lupus Erythematosus. Journal Of Investigative Dermatology, Reino Unido, v. 125, n. 5, p.889-894, nov. 2005. Disponível em: <http://www.nature.com/jid/journal/v125/n5/full/5603605a.html>. Acesso em: 14 jun. 2015.

ANYANWU, C.; LANGENHAN, J.; WERTH, V. P.. Measurement of disease severity in cutaneous autoimmune diseases. F1000prime Rep, v. 5, n. , 3 jun. 2013. DOI: 10.12703/p519. Disponível em: <http://www.ncbi.nlm.nih.gov/pmc/articles/PMC3673224/>. Acesso em: 15 jun. 2015.

BELMONT, H. M.. Treatment of systemic lupus erythematosus. Bulletin Of The Hospital For Joint Diseases, v. 71, n. 3, p.208-213, 2013. Disponível em: <http://www.ncbi.nlm.nih.gov/pubmed/24151947>. Acesso em: 15 jun. 2015.

BERBERT, A. L. C. V.; MANTESE, S. A. O.. Lúpus eritematoso cutâneo: aspectos clínicos e laboratoriais. Anais Brasileiros de Dermatologia, v. 80, n. 2, p.119-131, 2005. DOI: 10.1590/s0365-05962005000200002. Disponível em: $<$ http://www.scielo.br/scielo.php?script=sci_arttext\&pid=S0365-05962005000200002>. Acesso em: 15 jun. 2015.

BEZERRA, E. L. M.; VILAR, M. J. P.; BARBOSA, O. F. C.; SANTOS, S. Q.; CASTRO, M. A; TRINDADE, M. C.; SATO, E. I.. Lúpus eritematoso sistêmico (LES): perfil clínicolaboratorial dos pacientes do Hospital Universitário Onofre Lopes (UFRN-Natal/Brasil) e índice de dano nos pacientes com diagnóstico recente. Revista Brasileira de Reumatologia, São Paulo, v. 45, n. 6, p.339-342, 2005. DOI: 10.1590/s048250042005000600002. Disponível em: <http://api.elsevier.com/content/article/PII:S048250042005000600002? httpAccept=text/xml>. Acesso em: 16 jun. 2015.

BORBA, E. F.; LATORRE, L. C.; BRENOL, J. C. T.; KAYSER, C.; SILVA, N. A.; ZIMMERMANN, A. F.; PADUA, P. M.; COSTALLAT, L. T. L.; BONFA, E.; SATO, E. I.. Consenso de lúpus eritematoso sistêmico. Revista Brasileira de Reumatologia, São Paulo, v. 48, n. 4, p.196-207, 2008. DOI: 10.1590/s0482-50042008000400002. Disponível em: <http://api.elsevier.com/content/article/PII:S0482-

50042008000400002?httpAccept=text/xml>. Acesso em: 16 jun. 2015.

BRAGA, J. A. P.; HOKAZONO, M.; TERRERI, M. T. R. A.; HILÁRIO, M. O. E.. Púrpura trombocitopênica imunológica como manifestação inicial de lúpus eritematoso sistêmico juvenil. Revista Brasileira de Reumatologia, São Paulo, v. 43, n. 6, p.392-396, 2003. DOI: 10.1590/s0482-50042003000600013. <http://api.elsevier.com/content/article/PII:S0482Disponível em: 50042003000600013?httpAccept=text/xml>. Acesso em: 16 jun. 2015. 
BUENO, V.; PACHECO-SILVA, A.. Tolerância oral: uma nova perspectiva no tratamento de doenças autoimunes. Revista da Associação Médica Brasileira, São Paulo, v. 45, n. 1, p.7985, 1999. DOI: 10.1590/s0104-42301999000100014. Disponível em: $<$ http://api.elsevier.com/content/article/PII:S010442301999000100014?httpAccept=text/xml>. Acesso em: 16 jun. 2015.

DAHL C.; JOHANSEN C.; KRAGBALLE K.; OLESEN A. B.. Ustekinumab in the Treatment of Refractory Chronic Cutaneous Lupus Erythematosus: A Case Report. Acta DermatoVenereologica, doi: 10.2340/00015555-1467, 2013. Disponível em:

<http://www.researchgate.net/publication/232087539_Ustekinumab_in_the_Treatment_of_Re fractory_Chronic_Cutaneous_Lupus_Erythematosus_A_Case_Report>. Acesso em: 15 jun. 2015.

EASTHAM, A. B.; VLEUGELS, R. A.. Cutaneous Lupus Erythematosus. Jama Dermatology, v. 150, n. 3, p.344-344, 1 mar. 2014. DOI: 10.1001/jamadermatol.2013.10393. Disponível em: <http://archderm.jamanetwork.com/article.aspx?articleid=1843885>. Acesso em: 15 jun. 2015.

FILHO, J. P. M.; MELO S. D.; FREIRE E. A. M.; PEIXOTO R. L.; CARVALHO L. L.; MARTINS L. G.; PEREIRA A. K. F. T. C.. Lupus erythematosus: considerations about linical, cutaneous and therapeutic aspects. An Bras Dermatol, 89(1):118-25, 2014. Disponível em: <http://www.ncbi.nlm.nih.gov/pmc/articles/PMC3938362/>. Acesso em: 15 jun. 2015.

FREITAS T. H. P.; PROENÇA N. G.. Chronic cutaneous Lupus erythematosus: study of 290 patients. An bras Dermatol, Rio de Janeiro, 78(6):703-712, nov./dez. 2003. Disponível em: <http://www.scielo.br/pdf/abd/v78n6/18357.pdf >. Acesso em: 15 jun. 2015.

GRÖNHAGEN, C. M.; NYBERG, F.. Cutaneous lupus erythematosus: an update. Indian Dermatol Online J, v. 5, n. 1, p.7-13, 2014. DOI: 10.4103/2229-5178.126020. Disponível em: <http://www.ncbi.nlm.nih.gov/pmc/articles/PMC3937495/>. Acesso em: 15 jun. 2015.

GUILLERMO, N.; PEÑATE, Y.; MACHÍN, B. H.; BORREGO, L.. Refractory Subacute Cutaneous Lupus Erythematosus With a Response to Efalizumab. Actas Dermosifiliogr, v. 100, $2009.734-735$, Disponível em: $<$ http://apps.elsevier.es/watermark/ctl_servlet?_f=10\&pident_articulo=90183507\&pident_usu ario $=0 \&$ pcontactid $;=\&$ pident revista $=403 \&$ ty $=159 \&$ accion $=$ L\&origen $=$ actasdermo $\& w e b=w$ $\underline{w}$.actasdermo.org\&lan $=$ en \&fichero $=403 \mathrm{v} 100 \mathrm{n} 08 \mathrm{a} 90183507 \mathrm{pdf001.pdf}>$. Acesso em: 15 jun. 2015.

KLEIN, R.; KIA, S. M.; LOMONICO, J.; OKAWA, J.; COLEY, C.; TAYLOR, L.; TROXEL, A. B.; WERTH, V.P.. Development of the CLASI as a Tool to Measure Disease Severity and Responsiveness to Therapy in Cutaneous Lupus Erythematosus. Arch Dermatol, v. 147, n. 2, p.203-208, 1 fev. 2011. DOI: 10.1001/archdermatol.2010.435.

Disponível em: <http://www.ncbi.nlm.nih.gov/pubmed/21339447>. Acesso em: 16 jun. 2015.

KUHN, A.; STICHERLING, M.; BONSMANN, G.. Clinical Manifestations of Cutaneous Lupus Erythematosus. JDDG, v. 5, n. 12, p.1124-1137, 27 dez. 2007. DOI: 10.1111/j.1610- 
0387.2007.06554.x. Disponível em: <http://onlinelibrary.wiley.com/doi/10.1111/j.16100387.2007.06554.x/abstract>. Acesso em: 15 jun. 2015.

LEHMAN, T. J. A.; SINGH, C.; RAMANATHAN, A.; ALPERIN, R.; ADAMS, A.; BARINSTEIN, L.; MOORTHY, N.. Prolonged improvement of childhood onset systemic lupus erythematosus following systematic administration of rituximab and cyclophosphamide. Pediatric Rheumatology, v. 12, n. 1, p.3-9, 2014. DOI: 10.1186/15460096-12-3. Disponível em: 〈http://www.ped-rheum.com/content/12/1/3 >. Acesso em: 15 jun. 2015.

LORA, P. S.; LAURINO, C. C. F. C.; FREITAS, A. E.; BRENOL, J. C. T.; MONTECIELO, O.; XAVIER, R. M.. Padrões de imunofluorescência do fator antinuclear (FAN) em células HEp-2 de soros reagentes para anti-SSA/Ro. Revista Brasileira de Reumatologia, São Paulo, v. 47, n. 1, p.4-9, 2007. DOI: 10.1590/s0482-50042007000100003. Disponível em: <http://api.elsevier.com/content/article/PII:S0482-

50042007000100003?httpAccept=text/xml>. Acesso em: 16 jun. 2015.

MARÇON, C. R.; MORAES, M. R.; LANZELOTTI, S. M.; SIMIS, D. R. C.; NOVAES, G. S.. Marcadores de envolvimento sistêmico no lúpus eritematoso crônico discóide. Revista Brasileira de Reumatologia, São Paulo, v. 44, n. 5, p.333-338, 2004. DOI: 10.1590/s048250042004000500004. Disponível em: <http://api.elsevier.com/content/article/PII:S048250042004000500004?httpAccept=text/xml>. Acesso em: 16 jun. 2015.

MARTÍNEZ, A. C.; ALVAREZ-MON, M.. O sistema imunológico (I): Conceitos gerais, adaptação ao exercício físico e implicações clínicas. Revista Brasileira de Medicina do Esporte, Niterói, v. 5, n. 3, p.47-54, 1999. Disponível em: <http://www.scielo.br/scielo.php?script=sci_arttext\&pid=S1517-86921999000300010>.

Acesso em: 16 jun. 2015.

MERRILL, J. T.; BUYON, J. P.; FURIE, R. A.; LATINIS, K. M.; GORDON, C.; HSIEH, H. J.; BRUNETTA, P.. Assessment of flares in lupus patients enrolled in a phase II/III study of rituximab (Explorer) .Lupus, v. 20, n. 7, p.709-716, 8 abr. 2011. DOI: 10.1177/0961203310395802. Disponível em: <http://www.ncbi.nlm.nih.gov/pubmed/21478286>. Acesso em: 16 jun. 2015.

NAKASHIMA, C. A. K.; GALHARDO, A. P.; SILVA, J. F. M.; FIORENZANO, G. R.; SANTOS, A. B. S.; LEITE, M. F. S.; NOGUEIRA, M. A.; MENOLLI, P. V. S; MENOLLI, R. A.. Incidência e aspectos clínico-laboratoriais do Lúpus eritematoso sistêmico em cidade do Sul do Brasil. Revista Brasileira de Reumatologia, São Paulo, v. 51, n. 3, p.235-239, 2011. DOI: 10.1590/s0482-50042011000300004. Disponível em: $<$ http://api.elsevier.com/content/article/PII:S048250042011000300004?httpAccept=text/xml>. Acesso em: 16 jun. 2015.

PODCASTING BRASIL. Boletim Medicina e Saúde. Teste torna improvável o diagnóstico de lúpus em casos de FAN positivo com padrão pontilhado fino de. 2011. Disponível em: $<$ http://www.fleury.com.br/medicos/educacaomedica/podcast/Pages/default.aspx?url=/2011/06/10/teste-to $>$. Acesso em: 31 mar. 2015.

ROMITI, N. ; DINATO, S. L. M. ; ALMEIDA, J. R. P. ; LAPOLI, A. ; SEMENTILLI, A.. Lúpus eritematoso cutâneo subagudo apresentando-se como eritema anular centrífugo. Anais 
Brasileiros de Dermatologia, Rio de Janeiro, v. 79, n. 3, p.335-351, 2004. DOI: 10.1590/s0365-05962004000300011.

$\langle$ http://www.scielo.br/scielo.php?pid=S0365-05962004000300011\&script=sci_arttext $>$.

Acesso em: 15 jun. 2015.

SATO, E. I.; BONFÁ ,E. D.; COSTALLAT, L. T. L.; SILVA, N. A.; BRENOL, J. C. T.; SANTIAGO, M. B.; SZAJUBOK, J. C. M.; RACHID-FILHO, A.; BARROS, R. T.; VASCONCELOS, M.. Lúpus eritematoso sistêmico: acometimento cutâneo/articular. Revista da Associação Médica Brasileira, São Paulo, v. 52, n. 6, p.384-386, 2006. DOI: 10.1590/s0104-42302006000600012. Disponível em:

<http://api.elsevier.com/content/article/PII:S010442302006000600012?httpAccept=text/xml> . Acesso em: 16 jun. 2015.

TEIXEIRA, T. M.; COSTA, C. L.. Papel da vitamina D no lúpus eritematoso sistêmico. Revista de Nutrição, Campinas, v. 25, n. 4, p.531-538, 2012. DOI: 10.1590/s1415-52732012000400010. Disponível em: <http://www.scielo.br/scielo.php?script=sci_arttext\&pid=S1415-52732012000400010 > Acesso em: 15 jun. 2015.

UVA, L.; MIGUEL, D.; PINHEIRO, C.; FREITAS, J. P.; GOMES, M. M.; FILIPE, P.. Cutaneous Manifestations of Systemic Lupus Erythematosus. Autoimmune Diseases, v. 2012, p.1-15, 2012. DOI: 10.1155/2012/834291. Disponível em: <http://www.hindawi.com/journals/ad/2012/834291/>. Acesso em: 16 jun. 2015.

WINKELMANN, R. R.; KIM, G. K.; DEL-ROSSO, J. Q.. Treatment of Cutaneous Lupus Erythematosus: Review and Assessment of Treatment Benefits Based on Oxford Centre for Evidence-based Medicine Criteria. The Journal Of Clinical And Aesthetic Dermatology, v. $6, \quad$ n. $1, \quad$ p.27-28, 2013. Disponível em: <http://www.ncbi.nlm.nih.gov/pmc/articles/PMC3543290/>. Acesso em: 16 jun. 2015. 